\title{
TRADICIÓN JESUITA EN LA ELUCIDATA GRAMMATICA DE VARGAS
}

\author{
María Luisa HaRTo TRUJiLlo \\ Universidad de Extremadura*
}

Resumen

En 1711 Juan García de Vargas, prefecto y profesor de gramática y de retórica latinas en el Colegio Imperial de los jesuitas en Madrid, publica una gramática latina titulada Elucidata Grammatica Latina ad strictam Artem redacta. Con ella Vargas pretende completar y desarrollar las de los Padres Juan Luis de la Cerda y Álvarez y, sobre todo, mantener los métodos propios de esas gramáticas jesuitas, rechazando los nuevos aires racionales que dominaban ya la gramática en Europa tras el éxito allí de la Minerva sanctiana.

Palabras clave: Vargas, gramática latina, Elucidata, jesuitas, Brocense.

\section{JESUIT TRADITION IN THE ELUCIDATA GRAMMATICA BY VARGAS}

\section{Abstract}

Juan García de Vargas, prefect and teacher of Latin grammar and rhetoric in the Jesuit Imperial College in Madrid, publishes in 1711 a Latin grammar titled Elucidata Grammatica ad strictam Artem redacta. With it Vargas tries to complete and to develop the grammars of the Fathers Juan Luis de la Cerda and Álvarez and, especially, to support the methods of these Jesuit grammars, rejecting the new rational airs that dominate Europe after the success of the Sanctius' Minerva there.

Keywords: Vargas, Latin Grammar, Elucidata, jesuits, Brocense.

* Este artículo se enmarca en el proyecto de investigación Gramáticas en Europa (ss. XVII-XVIII). Estudios y ediciones (FFI2016-78496-P), dirigido por Eustaquio Sánchez Salor y María Luisa Harto Trujillo. 


\section{INTRODUCCIÓN}

Madrid, Colegio Imperial de los Jesuitas, año 1711. Juan García de Vargas, miembro de la Compañía, maestro y Prefecto del citado Colegio, publica una gramática latina titulada Elucidata Grammatica Latina ad Strictam Artem Redacta. Es una obra extensa, de 370 páginas, en 4 libros, con pretensiones didácticas y de totalidad, con aspectos de fonética, morfología, sintaxis, retórica..., que sigue la senda de los tratados jesuitas del Padre Álvares (1572) y del Arte Regia de Juan Luis de la Cerda (1601).

Es una gramática que mira, pues, al pasado, a la gramática tradicional, aunque también tiene pretensiones de futuro, ya que, por un lado, pretende completar aspectos de las gramáticas de Álvares y De la Cerda ${ }^{1}$ y, por otro lado, critica a ciertos adversarios con los que no está de acuerdo en algunas cuestiones gramaticales y a los que pretende iluminar con su gramática 'Aclarada'.

Estas críticas, sin duda, se dirigen contra El Brocense, cuya Minerva había alcanzado gran fama a lo largo del siglo XVII en toda Europa y que, a pesar de las dificultades, iba conociéndose poco a poco en nuestro país, gracias a la labor de discípulos de Sanctius, que estaban dando a conocer su doctrina en comentarios a la sintaxis de Nebrija ${ }^{2}$, y gracias

${ }^{1}$ En efecto, si en el libro II, el de la Sintaxis, reconoce que sigue a estos dos autores en sus reglas (Eluc. pág. 115), sin embargo, también en varias ocasiones valora sus aportaciones personales a dichas reglas. Así, en la pág. 235: «Pasemos a las reglas de la prosodia latina siguiendo el orden observado por Nebrija en su Arte Común, pero añadiendo, según convenga, algunas notas a cada una de esas reglas» (las traducciones aportadas de la Elucidata son nuestras). Y, en efecto, este es el procedimiento que sigue en la sintaxis. Valga como ejemplo, la regla 62 acerca de los supinos en -um (pág. 177), en la que toma las afirmaciones generales y algunos ejemplos de las gramáticas citadas (Arte Regia, pág. 142; De Institutione liber II, págs. 236-237), pero añade algunas citas y una nota $3^{\mathrm{a}}$, sobre las variaciones poéticas de dicha construcción.

${ }^{2}$ Estos comentarios eran el recurso utilizado para difundir doctrina racional salvando la prohibición de publicar gramáticas completas que se opusieran al Arte Regia. Entre ellos, podemos destacar el de Diego López que, aunque se titula Commento en defensa del libro quarto del Arte de Grammatica del Maestro Antonio de Nebrissa (publicado en Salamanca, 1610), expone en realidad doctrina de Sánchez (Morcillo Expósito, 2002; Merino Jerez, 1989: 189 sigs.). Y un caso similar lo encontramos en otro seguidor de Sanctius, Caro y Cejudo, que escribe una Explicación del libro IV y V del Arte Nuevo de Grammatica, publicada en Madrid en 1667, y que se reimprimió, modificó y amplió a lo largo del XVIII. Es significativo que Vargas menciona en su Elucidata (pág. 181) una de estas ediciones (la de Madrid de 1705), criticando la doctrina allí vertida. 
igualmente a la difusión de gramáticas europeas influidas por él, como las de Arnauld, Lancelot, Vossius o Beauzée, quienes partían de un enfoque enciclopédico, lógico, filosófico, didáctico, de defensa de la brevedad, de la claridad y, en cualquier caso, totalmente alejado de la memorización jesuita, promoviendo que la luz de la razón se extendiera a todos los ámbitos de la enseñanza.

Motivos, pues, religiosos, filosóficos, educativos y lingüísticos explican las críticas generales que contra la gramática racional lanza Vargas en su Elucidata, unas críticas que arrecian y se concretan aún más en un apéndice añadido tras su obra mayor. Nos referimos a la Antibrocensis Crisis o 'Juicio contra el Brocense', un tratadito de cincuenta páginas, que ocupa los cinco primeros capítulos del apéndice, y que nuestro jesuita afirma haber incluido porque, cuando escribió su Elucidata, no disponía aún de un ejemplar de la Minerva (Antib. pág. 2)

Pero, centrémonos en el análisis de cuáles son los aspectos tradicionales que Vargas pretende mantener y completar en su obra, aspectos que explican su propia edición y su crítica contra la gramática racional.

\section{ANTECEDENTES DE LA ELUCIDATA}

Si reflexionamos sobre la historia de la gramática latina desde la Antigüedad, es fácil advertir cómo esta avanzó con movimientos oscilantes, pues si, por un lado, encontramos gramáticas centradas en la morfología, en rudimentos y cuestiones ancilares de la retórica, porque se planteaban el estudio gramatical como un primer paso hacia esas disciplinas `superiores' de retórica y dialéctica, observamos también que, por otro lado -y frente a ellas-, surgen gramáticas que pretenden completar y superar a las citadas, y que planteaban un estudio más teórico y reflexivo, no tan enfocado a las partes de la oración y a cuestiones literarias, cuanto a la organización de la frase y a la comprensión del proceso lingüístico.

De ahí, por ejemplo, la aparición en el siglo VI d.C. de las Institutiones de Prisciano frente al Ars de Donato, en un intento de escribir una obra más completa y avanzada, que introducía la sintaxis en la gramática latina. De ahí también que, frente a Prisciano, aparezcan en el siglo XII 
obras didácticas en verso que, como el Doctrinal de Villadei, vuelve a la enseñanza de rudimentos y morfología mediante el uso de la memoria.

Como contrapartida, pasaríamos a las gramáticas modistas, que comentan y desarrollan las Institutiones de Prisciano con un planteamiento lógico y filosófico, partiendo de la distinción entre realidad, pensamiento y lenguaje. Lógicamente, esa especulación medieval, muy alejada de la enseñanza de la gramática a unos alumnos que desconocen la lengua latina, lleva a que, en los inicios del Renacimiento, encontremos las primeras gramáticas humanistas, como las Elegancias de Valla (1471), las Regulae de Guarino (1418), diversos Progymnasmata y Rudimenta, o las Institutiones de Nebrija (1481), que luchan contra esa teorización excesiva, contra el latín bárbaro de los modistas, y que vuelven a basarse en la fonética y morfología, el usus de los auctores clásicos y en aspectos retóricos que explican el latín de esos auctores como una lengua literaria, conformada mediante figuras retóricas o uirtutes, opuestas a los uitia.

Es esta línea de gramáticas normativas, compendios de listas, reglas y excepciones, con aspectos de retórica, con pretensiones de totalidad, basadas en el usus y en las auctoritates, la que seguirán a lo largo del XVI los gramáticos jesuitas, tanto más cuando, por resolución real, en 1594, se establece que la gramática latina debe enseñarse en Castilla por el Arte de Nebrija, resolución que se plasmará ya en una Cédula de 1598, en la que se establece que ha de enseñarse por ese Arte, si bien reformada, lo cual dará paso al llamado Arte Regia de Juan Luis de la Cerda, o Arte Común .

Ahora bien, siguiendo el movimiento oscilante que comentábamos, es comprensible que, ya a mediados del XVI, y frente a esta línea didáctica y tradicional, hubiera surgido la gramática de las Causas, que con el $D e$ Emendata de Linacro (1524), el De Causis de Escalígero (1540) y la Minerva del Brocense (1587), se planteaba el hecho lingüístico como una facultad del hombre que integra pensamiento y lenguaje, y que, por tanto, pretendía en-

${ }^{3}$ Cf. Sánchez Salor (2002: 164-184) considera que las diferencias entre el Arte Reformado de 1601 son tantas respecto a la versión de 1598, que el autor de esta última no puede ser el propio De la Cerda; Gómez Gómez (2013: XVI-XXX); o Martínez Gavilán (2008: 201). Como indica Espino (2005: 218), los añadidos que introduce De la Cerda sobre el Antonio se centran en poner en español las reglas del libro $1^{\circ}$, modificar los versos oscuros y añadir notas en castellano en el libro $2^{\circ}$, suprimir los erotemata y añadir también notas en español en el $3^{\circ}$, y ya, en el $4^{\circ}$, incluir 48 notas explicativas en castellano. 
señar gramática latina centrándose en la ratio, en el análisis de cómo se genera la frase desde una estructura mental o iusta, hasta una estructura figurata o de realización. Este punto de partida dio lugar así de nuevo al dominio de la sintaxis, si bien se trataba ahora de una sintaxis racional ${ }^{4}$.

Pues bien, esta gramática de las causas, que encuentra su máximo exponente en la Minerva sanctiana de 1587, tendrá pronto éxito en toda Europa. No en vano, para Bassols de Climent (1945: 51): «En el extranjero el triunfo del Brocense sobre Nebrija fue definitivo y completo. Nadie volvió a mencionar ni a recordar a este último» ${ }^{5}$.

\subsection{Tratados jesuitas: Álvares y De la Cerda}

Sin embargo, en España, a lo largo del XVII y los primeros años del XVIII, se olvida en gran medida al Brocense ${ }^{6} \mathrm{y}$, tal como hemos apuntado, seguimos encontrando el Nebrija reformado, o bien, sobre todo en los colegios jesuitas y como complemento al anterior, se usa la sintaxis de Álvares ${ }^{7}$, además de tratados jesuitas menores sobre los modos y los tiempos, el género del nombre, etc. ${ }^{8}$

${ }^{4}$ De ahí, por ejemplo, las críticas del Brocense contra los primeros gramáticos humanistas como Valla, a quien considera una fuente turbia y cenagosa, de la que nacen riachuelos, seguramente tan turbios como él. Cf. Minerva praef. págs. 34; 78, 80, 384 y 404 . Y una queja similar podemos encontrarla en el De causis de Escalígero de 1540 (Epist. Seb. Gryphio, Lyon, 2; cf. Sánchez Salor, 2002: 16).

${ }^{5}$ Acerca del éxito del Brocense en Europa, véanse Sánchez Salor (2000b: 207-222), Espino (2005: 267 sigs.), Breva Claramonte (1980: 351-371)...

${ }^{6}$ Son incontables las citas que podríamos aducir sobre este olvido. Baste mencionar a Lázaro Carreter (1985: 153-163), Breva Claramonte (1980: 351 sigs.) o Espino (2010: 61 sigs.).

${ }^{7}$ Quien había compuesto un De Institutione grammatica libri tres (Lisboa 1572), aunque el libro que más se difundió, el $2^{\circ}$, era el de la sintaxis (De constructione octo partium orationis), que se reimprimió varias veces en España adaptando las traducciones y los ejemplos originales al español. Así, se reimprime en Sevilla 1573, Burgos 1574, Córdoba 1588, Alcalá 1589 y 1597, Barcelona 1596 y Madrid 1587 o 1593. No obstante, la difusión de la doctrina alvaresiana (Ponce de León, 2005: 365 sigs.) provocó gran polémica en España, empeñados muchos autores en que no se rompiera el monopolio de Nebrija. Pese a ello, el conjunto de los tres libros también se imprimió en una edición adaptada a profesores y alumnos españoles (Lisboa 1578).

${ }^{8}$ El propio Vargas escribió alguno de estos tratados escolares, que intentan desarrollar las reglas de Nebrija, y que se publicaron muchas veces con seudónimos, ya que sus autores escribían igualmente una obra mayor, por la que pretendían ser conocidos. Así Vargas publicó dos trataditos con el seudónimo de Tomás García de Olarte (Uriarte, 1906, III: 205206 y 366; Ponce de León, 2004: 1296; 2003: 136). Son sus Observaciones selectas de los modos de las oraciones latinas, conforme se enseñan en los estudios de la Compañía de 
Son muy significativas en este sentido las palabras del Barbadiño ${ }^{9}$ acerca de la culpa que tienen los jesuitas del olvido del Brocense: «Los doctísimos Jesuitas enseñan gran parte de la mocedad en varias partes de Europa, y no queriendo apartarse de su Manuel Álvarez despreciaron todas las nuevas gramáticas» ${ }^{10}$.

Es decir, en líneas generales, a lo largo del XVII en nuestro país, encontramos obras en las que la sintaxis, partiendo del Nebrija reformado o de Álvares, se basa en listas, reglas, excepciones y notas, lo cual genera gramáticas extensas, con pretensiones de totalidad, con muchas citas de autores clásicos, basadas en la memorización y con elementos de fonética, morfología, etimología, métrica, prosodia, retórica... ya que, como indica Espino (2005: 113), «la sistematización y minuciosidad de la pedagogía alvaresiana para la enseñanza del latín se correspondía plenamente con el afán de las Rationes de Acquaviva de sumergir al alumno en toda una serie de reglas y preceptos que controlasen totalmente su formación educativa».

A los jesuitas les interesaba que se estudiara la gramática latina como el puntal sobre el que asentar luego las demás artes, que permitirían formar cristianos buenos y elocuentes, defensores de la $\mathrm{fe}^{11}$. No había que

Jesús, que según indica el propio Vargas en la Elucidata, habría sido compuesto en 1696; o su Explicación y construcción de las reglas de géneros y pretéritos. Conforme se enseñan en los Estudios de la Compañía de Jesús..., Barcelona, 1700. Eso sí, en la Elucidata, Vargas afirma que quiere completar y desarrollar dichos tratados para que no se eche nada en falta (pág.22).

${ }^{9}$ Pseudónimo del ilustrado portugués Luís António Verney.

${ }^{10}$ Verney (1768: 114). Cf. Espino (2010: 63; 2005: 268). Frente a la opinión del Barbadiño, Bartolomé (1995: 145), recoge una cita de Menéndez Pelayo en la que se afirma que no eran acertadas esas críticas del Barbadiño contra Álvares, ya que este era un humanista bastante mejor que él.

${ }^{11}$ Como afirma el P. Bonifacio en su Carta séptima, a un joven jesuita, «Si la república necesita buenos edificios, nuestros gramáticos son los carpinteros que sustentan la techumbre; si hay que adornar las casas con estatuas y pinturas, los retóricos se encargan de eso, pues no hay cuadro ni adorno que se pueda comparar con las lumbres y figuras de un hermoso discurso. Alabemos, pues, a los que cultivan las bellas letras, amémoslos, admirémoslos y honremos cuanto sea posible los estudios de humanidad. Ellos pulen a nuestros dialécticos y a nuestros filósofos y teólogos, nos consuelan en nuestros trabajos y dolores, nos ponen en comunicación con otros pueblos, nos concilian las voluntades de los enemigos de nuestra fe y la atención de los que nos oyen, con ellos, finalmente, se nutren los maestros de los niños, mejor dicho, los doctores de la sabiduría, los guardianes de la pureza, los mantenedores de las leyes, los restauradores de la antigua santidad y de la vieja disciplina» (apud Espino, 2005: 60). 
entender la lengua latina ni sus causas, había que memorizar declinaciones, conjugaciones, reglas y excepciones, pues solo mediante la memoria, el alumno podría dominar la lengua y realizar así él mismo composiciones en latín, hablado o escrito.

Eso no significa que la doctrina racional fuera desconocida en el XVII, ya que, en el propio Arte Regia, aparecen aspectos racionales, tomados del De Emendata de Linacro (1524), de Álvares (1572) ${ }^{12}$, de los Commentarii de Despauterio $(1537)^{13}$ o del propio Brocense $(1587)^{14}$.

Estos aspectos racionales son visibles en la sintaxis. Así, en la distinción entre constructio iusta y figurata; en el tratamiento de las figuras de construcción incluido en la sintaxis y no tratado de manera muy resumida en el libro III; en el tratamiento de los casos comunes a todos los verbos; en la construcción de los numerales; o en una reestructuración de la materia que permite, por ejemplo, que se pase de la estructura tradicional de Nebrija, que analiza primero el verbo y después el nombre, a una estructura más lógica y racional, que comienza por el nombre para pasar al verbo ${ }^{15}$.

${ }^{12}$ Cf. Ponce de León (2003: 133-134; 2004: 1295 sigs.), Sánchez Salor (1999: 117-119; 2000a: 350) o Espino (2005: 233 sigs.). Como indica Martínez Gavilán (2008: 208): «La mayor parte de las modificaciones llevadas a cabo por Juan Luis de la Cerda sobre las Introductiones Latinae vienen dadas por su aproximación deliberada a los contenidos y estructura de la gramática de Álvares, obra que le proporciona el conjunto de reglas o preceptos que constituyen los cimientos del Arte reformado. En consecuencia, es de ella, en realidad, de la que procede el trasfondo doctrinal al que se superponen los postulados sanctianos». Cf. Ibid. pág. 231.

${ }^{13}$ La obra de Despauterio se usó mucho en los colegios jesuitas de la península desde el XVI, ya que fue la gramática imperante en la Universidad de París, donde se habían formado algunos jesuitas que enseñaron luego en la península (Sánchez Salor, 2012: 23). Este mismo autor señala que dicha obra fue la preferida por los jesuitas hasta que apareció la de Álvares, pues antes de eso no contaban con manuales de miembros de la Compañía (Sánchez Salor, 2002: 132).

${ }^{14}$ Cf. Ponce de León (2001: CXXIII-VIII; CLVI-VII), Gómez Gómez (2002: XXVIII-XLI), Espino (2005: 257).

${ }^{15}$ No es extraño, pues, que se defienda que «el texto que pasará a la historia de la gramática española es el De Institutione, que ya no es el texto de Nebrija... Su autor sigue en general el índice de las Introductiones de Nebrija, excepto en el caso del libro III, que queda reducido...; suprime las glosas originales de Nebrija, añade otras, y escribe gran parte del texto en romance. De la Cerda tiene en cuenta la breve historia de las partes de la oración que introduce Sánchez de las Brozas (1523-1600) en la Minerua (1587) y comparte con él su concepción del pronombre, participios e interjección como elementos que no forman partes autónomas de la oración. Como Sánchez de las Brozas, niega la existencia de verbos 


\section{Como indica Ramajo Caño (1991: 320):}

La huella del Brocense en el Arte de La Cerda es abundante. Su redacción en español (al menos, en gran parte); su concepción del pronombre, del participio y de la interjección como elementos que no forman partes autónomas de la oración; su concepción de los verbos impersonales y neutros, constituyen deudas contraídas con la $\mathrm{Mi}$ nerva de 1587.

Es lógico que, tras el tiempo trascurrido desde la publicación del $A n-$ tonio (1481) hasta la versión reformada (1601), De la Cerda pretendiera no solo aclarar los aspectos más complicados, sino también actualizar un tanto esta obra, introduciendo -especialmente en las 48 notas que siguen a la sintaxis y que están dirigidas a los docentes-, aspectos tomados de Linacro, Despauterio, Álvares o del Brocense, que desarrollan y completan el contenido ${ }^{16}$.

En esas notas aparece, por ejemplo, en la 40 (pág. 187), doctrina racional sobre la elipsis de preposiciones en ciertas indicaciones de lugar entre historiadores y poetas, doctrina que había aparecido también en la obra del Padre Álvares (De const. pág. 183) y que, posteriormente, incluirá también Vargas en su Elucidata (pág. 195).

Es decir, el Arte Regia incluye aspectos de doctrina racional, que en algún caso serán retomados también por Vargas, si bien la diferencia con El Brocense es que, por ejemplo, Sanctius considera las elipsis procedimientos gramaticales que explican el funcionamiento de cualquier lengua, mientras que, para los jesuitas, son procedimientos retóricos usados por las auctoritates latinas ${ }^{17}$.

impersonales y se apoya en él expresamente para negar la existencia de verbos neutros... El nuevo Antonio -así se le llamaba- supone la prohibición del verdadero Antonio» (Esparza, 2006: 100-101).

${ }^{16}$ Cf. Rodríguez Aniceto (1931-1932: 236-238), Ramajo Caño (1991: 310 sigs.), Ponce de León (2003: 1295) y especialmente Sánchez Salor (1999: 117-119; 2000a: 350; 2002: 17985). Son significativas en este sentido notas como la 45 o la 48 sobre las conjunciones, que introducen doctrina racional acerca de una parte de la oración poco desarrollada por Nebrija y que, sin embargo, sí es muy citada en la gramática racional, preocupada por la sintaxis. Para Espino (2005: 234), en estas notas es claro el influjo de Álvares sobre De la Cerda.

${ }^{17}$ Es significativo, por ejemplo, que para Vargas no se puede sobreentender siempre un nombre junto a un adjetivo, como postula Sanctius, sino solo cuando así aparece en algún autor latino (Eluc. pág. 33). 
Con todo, en opinión de algún estudioso como Martínez Gavilán (2008: 204 sigs.), los aspectos racionales del Arte Regia se dan no solo en las notas, sino también en el propio cuerpo de la obra, especialmente en los libros III y IV, en los que se advertiría tanto el añadido de elementos, como la supresión de aquellos considerados superfluos (por ejemplo, las preguntas y respuestas, o la casuística del libro III), y una reestructuración de la materia, que supondría, por ejemplo, la inclusión de un capítulo sobre la construcción figurada en el libro IV, a lo que se suma la afirmación de que solo hay dos tipos de verbos (activos y pasivos), a los que otros añaden los neutros, comunes y deponentes (pág. 52), o la negación de los impersonales.

Así pues, el Arte Regia es una gramática didáctica, tradicional, con pretensiones de totalidad, basada en la memorización y con aspectos de retórica, como era propio de un jesuita que retoma la doctrina de Nebrija. Pero, bajo ese nombre de Antonio, incluye algún elemento moderno -aunque escaso- de Linacro, Despauterio, Alvarez y del Brocense, es decir, de los considerados «enemigos» del Antonio.

Vargas, cita una y otra vez el Arte Regia o Común y así, al hablar sobre el género del nombre, alude a lo que ya había aportado en sus Observaciones, y añade que toma como estructura la que aparece en el Arte Regia:

Como acerca del género de nombres en singular y sobre los pretéritos y supinos, en el año 1696, y nuevamente después también en Madrid, se imprimió un librillo que, por causas justas entonces apareció a nombre del maestro jesuita Juan García de Olarte ${ }^{18}$, podría en estas circunstancias, sin que se me adjudicara nota alguna de plagiario, retomar ahora esa obra así como su autoría. Por tanto, voy a repetir la misma doctrina sobre los géneros del nombre (tal como haré también en su momento sobre los pasados y supinos de los verbos) añadiendo tal vez alguna aportación, para que ningún estudioso eche en ningún momento nada en falta en nuestra gramática, y conservando el orden de las reglas del Arte Común de Nebrija (Eluc. pág. 22).

${ }^{18}$ Curioso lapsus de Vargas, que olvida aquí que su sobrenombre en estos tratados menores era Tomás García de Olarte, y utiliza su auténtico nombre, Juan. 
Y esa influencia es evidente, por ejemplo, en el libro $1^{\circ}$ de la Elucidata, a propósito de los nombres irregulares (págs. 13 sigs.), del género del nombre (págs. 26 sigs.), o en el libro $2^{\circ}$, el de la sintaxis, que sigue el orden establecido en el Arte Regia, pero desarrolla los comentarios y aporta muchos más ejemplos, tomados en gran medida de Álvares ${ }^{19}$.

En este aspecto del influjo de De la Cerda en Vargas, nos parece además significativo el que el primero había sido también Prefecto en el Colegio Imperial y maestro allí durante 45 años (de 1597 a 1642), siendo su método el utilizado en dicho Colegio (Bartolomé, 1995: 113, 141), que era además el que contaba con la exclusiva de revisión de las distintas ediciones, si bien se complementaba con el manual de Álvares y, en las aulas de mínimos y remínimos, con los librillos de géneros y pretéritos de algunos jesuitas, como el propio Vargas.

Con todo, ya hemos apuntado que, junto al influjo de De la Cerda, son evidentes también en la Elucidata algunas aportaciones atribuidas al P. Álvares, a pesar de que no siempre fue fácil la difusión de su obra en nuestro país ${ }^{20}$.

Así, ya hemos comentado que, si bien el Arte Regia dominaba la enseñanza en los colegios jesuitas, compartía ese uso con la obra de Álvares, pues, por ejemplo, según el Orden y distribución de los estudios del Colegio Imperial del P. Valdés (1639), en el aula de mínimos se enseñaban en el primer semestre los Rudimentos, las concordancias, las formaciones, los catorce preceptos de Alvarez, el género, pretéritos y supinos, que son reglas incluidas en los Rudimenta siue de octo partibus orationis, que Alvarez compuso como iniciación a la sintaxis y que complementaban a la recognitio de De la Cerda, que carecía de ellas (Ponce de León, 2003: 135-136).

${ }^{19}$ Así, por ejemplo, en la construcción figurada (Eluc. págs. 205 sigs.), en la que Vargas define las figuras de construcción siguiendo las opiniones y el orden de De la Cerda y de Álvares, pero introduce más ejemplos y subtipos que el primero, tal como había hecho ya Álvares.

${ }^{20}$ Ya hemos dicho que tuvo dificultades en España, pues el libro I era más apropiado para alumnos portugueses por los ejemplos; y porque la legislación castellana era muy restrictiva y no era fácil vencer los privilegios de impresión del Antonio, motivo por el que el libro que más se difundió en España fue el libro II, sobre la Sintaxis (Martínez Gavilán, 2008: 208-209; Ponce de León, 2003: 135). Al no ser una gramática completa, era más sencillo vencer los privilegios de Nebrija. 
Es evidente que Vargas conoce bien la obra de Álvares y, de hecho, le cita una y otra vez, le denomina noster ${ }^{21}$, eruditissimus (pág. 79), o se muestra de acuerdo con él (recte sentit, pág. 194). De él toma Vargas (Eluc. pág. 39) la doctrina sobre los modos del verbo (Esparza, 2006: 106107; Ponce de León, 2003: 136-139; Espino, 2005: 242-3); sobre la construcción transitiva-intransitiva (Eluc. págs.107-108) ${ }^{22}$; sobre la constructio iusta-figurata, o sobre la concordancia, lo cual lleva a Ponce de León (2003: 138) a concluir:

La influencia de los planteamientos de Manuel Álvares trasciende la estructuración de la sintaxis, ya que, en la Elucidata grammatica, hay reflejos de una lectura más que atenta de los De institutione grammatica libri tres.

Así pues, Álvares influye en Vargas tanto directamente, como de manera indirecta a través del Arte Regia, en el que, como hemos apuntado, había notable influencia también del portugués.

\subsection{Fuentes racionales: Sanctius y sus discípulos}

Ahora bien, junto a esos antecedentes, evidentes y fundamentales, de Álvares y De la Cerda, que le aportan la base doctrinal jesuita, hemos de señalar también que Vargas puede criticar la doctrina racional porque, si bien no disponía de la Minerva cuando escribió su Elucidata, sí conocía los comentarios que algunos discípulos del Brocense habían hecho del libro IV de Nebrija ${ }^{23}$, y que eran el medio usado por esos discípulos para

${ }^{21}$ Así, sobre el modo del verbo (Eluc. pág. 39): MODVS uerbi, ut pluribus grammaticis olim placuit, est uoluntas seu affectio animi per uocem adsignificata. Sed cum hominum affectiones seu uoluntates tam uariae sint... ut noster Emmanuel Aluarez aptissime notauit... También en la pág. 174, sobre el gerundio: Gerundia, ut cum Patre Emmanuele Aluarez opinor... Y le cita de nuevo acerca de la preposición in con ablativo (pág. 194); de la cantidad vocálica (pág. 243); del acento (págs. 284 y 287); de la declinación de nombres griegos (pág. 364)...

${ }^{22}$ Así lo apunta Ponce de León (2003: 138), que ve influjo de Alvarez en que Vargas considera transitivas construcciones que tradicionalmente se habían considerado intransitivas, como sum fortissimus o perge iucundissimus, entendiendo que tanto el atributo como el predicativo suponen un paso del significado entre dos partes orationis (Ponce de León, 2004: 1296), si bien Álvares no había extendido, como sí hace Vargas, el concepto de transitividad a otras partes orationis distintas al verbo y sus complementos, y tampoco había aportado al concepto de transitividad el matiz semántico que se percibe en nuestro autor.

${ }^{23}$ Por ejemplo, el Commento de Diego López (Morcillo Expósito, 2002). 
difundir doctrina de su maestro cuando, aparentemente, estaban explicando el Antonio.

Tal vez el caso más interesante en ese sentido, en relación con Vargas, lo encontramos en la Explicación del libro IV y V del Arte Nuevo de Grammatica, publicado en Madrid en 1667 por J. Martín Caro y Cejudo, discípulo de Sanctius, maestro en Valdepeñas, a quien I. del Campo denomina «el mayor campeón, el más acérrimo secuaz y el más valiente capitán de Sánchez» ${ }^{24}$.

Esta Explicación se reimprimió, modificó y amplió varias veces a lo largo del XVIII, produciéndose una de estas impresiones en Madrid, en 1705, a expensas de D. José del Villar y Villanueva, en cuya casa, en la calle Toledo -por tanto, junto al Colegio Imperial- se vendía esta obra. Es lógico, pues, que Vargas dispusiera de esta edición, y de hecho la menciona en su Elucidata (pág. 181) como obra de un autor reciente, sin citar su nombre, para no darle sin duda publicidad, mostrándose en desacuerdo con la doctrina allí vertida (Explic. págs. 396-397) acerca de los nombres posesivos y de su uso, semejante al posesivo reflexivo suus ${ }^{25}$.

Y lo que le critica, sobre todo, Vargas a Caro y Cejudo es que ofrece ejemplos de su doctrina, pero no da ninguna razón, lo cual es aprovechado por nuestro jesuita para introducir una cita -ahora sí- de la Minerva, en el sentido de que el uso sin razón no sirve de nada. Esta cita sanctiana había sido ya recogida por Caro y Cejudo (págs. VI y IX), mostrándonos así cómo, aunque Vargas no disponía aún de la Minerva cuando escribió su Elucidata, sí conocía sus tesis y algunas citas concretas gracias a estos comentarios de sus discípulos, para quienes apunta Vargas que las palabras de Sanctius son aurea (Eluc. pág. 182), y a quienes critica tanto como a su maestro (prout magister hic ipse cum Patrono suo Brocensi sentit), por expresar un pensamiento falsissimum e ineptissimum (pág. 183), regodeándose además Vargas en su crítica con

${ }^{24}$ Apud Cañigral (1989: 102) y Espino (2005: 264).

${ }^{25}$ Acerca de las dificultades de difusión de la doctrina sanctiana, Cañigral apunta que es muy raro que la $3^{\text {a }}$ edición de esta Explicación cuente con una aprobación de 1686, y que sin embargo la suma de la aprobación de privilegio por diez años corresponda ya a 1697, al igual que la suma de tasas y la fe de erratas, apareciendo la fecha de imprenta de 1705. Para Cañigral (1978: 63) todo ese desfase se debe a las dificultades -él dice 'labor de zapa'- que los jesuitas ponían a las obras alejadas de su método. 
el uso irónico del término Magister (pág. 184), e introduciendo su propia doctrina con la mención a la ratio: Cuius ratio est (ibid). Es decir, frente a lo que esperábamos, es Vargas el que ofrece las razones frente a los simples ejemplos de Sanctius y su discípulo. Incluso, se burla y afirma que la única manera de que resulte admisible la opinión de sus oponentes es partiendo de una construcción figurada por elipsis, con lo cual observamos una nueva inversión de papeles, al defender el jesuita en ese caso una construcción elíptica:

Propter expositas superius rationes easdem cogor asserere, et assero, omnia illa testimonia ab hoc Magistro in libro suo congesta eandem figuram eclipsim re uera includere... Figurata constructio ad id est potissimum inuenta, ut Auctorum testimonia explicatu difficilia declaremus, exprimendo ea, in quibus talia testimonia a plena, et legitima Grammaticali constructione deficiant (pág. 185).

Eso sí, como indica en ese pasaje, para él las construcciones figuradas sirven para explicar citas oscuras de las auctoritates, pero no constituyen un recurso gramatical propio del uso de la lengua, como planteaba El Brocense. Es decir, Vargas considera la elipsis una figura retórica, El Brocense una figura gramatical.

De manera similar, hay otro pasaje -acerca del helenismo- en el que Vargas demuestra conocer la obra de Caro y Cejudo y, por tanto, la doctrina sanctiana. Y es que, en la definición de helenismo, Vargas sigue a Álvares y De la Cerda:

Hellenismus est constructio quae Graeci sermonis leges non Latini obseruat (De Const. pág. 336)

Hellenismus est constructio quae Graeci sermonis leges non Latini obseruat (Arte Reg. pág. 196).

Hellenismus figura est qua Graeci sermonis leges non Latini, obseruantur (Eluc. pág. 208).

Ahora bien, mientras que De la Cerda se limita a ofrecer su definición y un ejemplo, Álvares desarrolla un poco el tratamiento de esta figura, citando a Prisciano, Linacro... y ofreciendo subtipos de helenismo y más citas. Pues bien, Vargas incluye también la ampliación de Álvares pero, además, habla de los helenismos que se producen cuando un caso que 
aparece entre dos verbos concierta con aquel por el que no es regido; o cuando se da una alteración de género, o se usa un genitivo por un ablativo con preposición (Eluc. pág. 209), apareciendo toda esta información adicional, justamente, con los mismos ejemplos en la Minerva (pág. 598) y en la Explicación de Caro y Cejudo (págs. 217 sigs.).

Así pues, creemos que, cuando Vargas escribe la Elucidata, no conoce la doctrina sanctiana directamente por la Minerva ${ }^{26}$, pero sí por las huellas que esta ha dejado en el Arte Regia, en gramáticas castellanas, o en los comentarios que los discípulos de Sanctius hacen del Antonio. De ahí que critique en la Elucidata la doctrina racional, pero con términos genéricos (alii, aduersarii...) ${ }^{27}$ y que haya que esperar a la Antibrocensis crisis, el apéndice que añade tras su gramática mayor, para encontrar una crítica dura y directa, que ataca, prácticamente página a página, la doctrina sanctiana.

Con todo, a pesar del atraso de nuestro país respecto a lo que ocurría en Europa, a pesar de los privilegios y del dominio casi exclusivo de los planteamientos de De la Cerda y Álvarez -sobre todo en los colegios castellanos- y, a pesar de lo difícil que era hacerse con un ejemplar de la Minerva, lo cierto es que en los inicios del XVIII la amenaza de la gramática racional y, sobre todo, de los nuevos métodos ilustrados era ya evidente, lo cual explicaría el último esfuerzo de un jesuita como García de Vargas por escribir, en 1711, una Elucidata Grammatica, que sigue la estela de las gramáticas de la Compañía y que, al igual que el resto de sus miembros, muestra un punto de vista ideológico, filosófico y educativo, muy alejado de las innovaciones que suponían el racionalismo, la Ilustración y los nuevos métodos de la Minerva o de Port Royal.

${ }^{26}$ Como indica Espino (2010: 70): «el Brocense es olvidado de tal manera que resulta casi imposible encontrar en España ediciones de la Minerva en la primera mitad del siglo XVIII», apuntando que en España no se dio ninguna edición de esta obra desde 1587 hasta 1762 (Espino, 2005: 255). Como ejemplos de esta dificultad, cita lo indicado por Vargas en el inicio de la Antibrocensis, o por Burriel en una carta dirigida a Mayans el 11 de junio de 1746.

${ }^{27}$ Así, en la pág. 98 acerca de los que plantean que la oración tiene que estar constituida, al menos, por nombre y verbo; en la 165 sobre elipsis ridículas, o en 190-191 criticando a los que plantean que dos oraciones son equivalentes por significar lo mismo. 


\section{ASPECTOS TRADICIONALES DE LA ELUCIDATA}

Si partimos del título de Elucidata grammatica Latina ad strictam artem redacta, destaca ya para nosotros que Vargas quería iluminar una gramática latina que, en su opinión, estaba a oscuras y necesitaba claridad. Además, pretendía lograr esa luz volviendo a lo anterior (redacta) y al rigor (strictam artem) del arte gramatical. Es decir, Vargas propone escribir un Arte aclarado y riguroso, frente a lo que preveía que podría imperar en su época. Él promete totalidad, rigurosidad, claridad, base firme... pero, curiosamente, no dice nada de la brevedad y sencillez, que es de lo que presumían Sanctius y sus seguidores, de manera que podemos considerar que su obra se enmarca bajo las directrices barroquizantes e hispanizantes que marcarían las gramáticas jesuitas del XVII ${ }^{28}$.

Su obra (págs. 1-2) comprende aspectos gramaticales (gramática methodica), pero también literarios y de comentario de autores (gramática historica), según la célebre distinción de Quintiliano (Inst. I 4,2), pues su fin último sería ayudar a los alumnos a componer una oración latina correcta, tanto en la pronunciación como en la escritura, atendiendo a cuestiones de fonética, morfología, sintaxis y retórica. No olvidemos que, para un jesuita, el dominio de la gramática latina era un paso previo y necesario para dominar la retórica y poder así evangelizar, de ahí que Vargas considere que su Elucidata es práctica, liberal y sermocinal (Eluc. pág. 2).

A continuación, apunta también Vargas (pág. 3) que son cuatro las partes de las que debe constar una gramática: sintaxis, prosodia, ortografía y etimología, correspondiendo las dos primeras al objetivo de hablar correctamente, mientras que las segundas se corresponderían más con aspectos de escritura, retóricos y de comentario de autores, para lo cual hay que partir de reglas, sencillas y ciertas, que se basen el usus de las auctoritates. El gramático debía enseñar a sus alumnos las letras latinas, para que avanzaran después, como buenos cristianos, por la comprensión de los textos, la métrica, la retórica y la composición. Había que entender y hablar bien latín, para poder catequizar.

${ }^{28}$ Directrices apuntadas por Espino (2005: 13), que se refiere a que son gramáticas muy recargadas en cuanto a reglas, excepciones, ejemplos, citas... además de utilizar frases o traducciones al español, que favorecerían la comprensión por parte de los alumnos. 
Para eso, es fundamental que el gramático establezca reglas partiendo del usus de los Auctores (1-2):

Ideo omnem Latinae orationis rectidudinem, tam quoad effectionem, seu compositionem, quam quoad prolationem et scriptionem amplectitur. Consequenterque regulas omnes circa triplicem hanc rectitudinem uersantes ex communi Latinorum Authorum classicorum usu collectas.

In communi omnium sensu ARS intelligitur Facultas ad suum finem consequendum agens rationale dirigens, per certas regulas ex communiori classicorum in tali materia Authorum usu collectas, atque Magistrorum labore ac obseruatione ordinatas.

Son estos catálogos de reglas los que debe memorizar el alumno para aprender los usos elegantes latinos. Así, por ejemplo, acerca de los nombres defectivos e irregulares, afirma Vargas: Sed nequis defectiuorum aut irregularium ignoratione laboret, ea mox in catalogum reducemus (Eluc. pág. 9).

Puede introducir algún aspecto racional como la distinción iusta o legitima-figurata ${ }^{29}$, pero lo que le interesa realmente es la constructio legitima, analizando solo la figurata en tanto en cuanto es una desviación literaria y retórica que aparece en el usus de los auctores. Para él, la sintaxis legítima no es, como en la gramática racional, aquella en la que figurarían todos los componentes, en el orden correcto y con la función propia de cada forma. Es la que se construye de acuerdo con las normas y reglas gramaticales, mientras que la figurada se aleja de esas normas, no por una figura de construcción como procedimiento gramatical, sino por alguna razón concreta, que ha de estar unida siempre al uso de un autor elegante.

La sintaxis de Vargas es así una exposición, incluso más minuciosa que las de De la Cerda o Álvares, de los que recoge reglas, notas y citas de autores clásicos, si bien desarrolla algunos aspectos, incluye ejemplos castellanos, etc. Así, por ejemplo, a propósito del supino en -um (Eluc.

${ }^{29}$ Compositio orationis ... duplex est: alia legitima, quia grammaticae artis praeceptis conformis; alia figurata (seu permissiua iuxta alios) quia ab aliquo grammaticae praecepto deficit, ratione aliqua aut classici latini auctoris usu innixa (Eluc. pág. 110). 
pág. 177), toma la doctrina de Álvares (pág. 236) y del Arte Regia (pág. 142), incorporando también los añadidos del jesuita portugués (pág. 237), pero ofrece un desarrollo original sobre otras construcciones que pueden sustituir a la citada, para lo cual cita varios ejemplos. Y lo mismo hace con el supino en $-u$ (pág. 178), para el que ofrece también ejemplos de construcciones alternativas, lo cual muestra su preocupación por enseñar un latín correcto, literario y elegante. Es decir, la Elucidata es una gramática elaborada como paso previo a la retórica y que, por tanto, sigue la senda de las obras jesuitas, mantiene sus métodos y objetivos tradicionales, criticando los aspectos novedosos, racionales y contrarios a su doctrina.

\section{CONCLUSIONES}

A principios del XVIII, la situación de la enseñanza de la gramática en España no era demasiado halagüeña. Los jesuitas dominaban dicha enseñanza, gracias a la imposición del Arte Regia, o al uso en sus colegios de la sintaxis del P. Álvares. Fuera de nuestro país, y especialmente en Francia, soplaban aires nuevos y la Minerva del Brocense, unida a los nuevos métodos racionales de la Ilustración, propugnaban una enseñanza más breve y lógica, más sencilla y con métodos que excluyeran la memorización y las reglas tan del gusto de los miembros de la Compañía.

En esa situación, J. García de Vargas, Prefecto del Colegio Imperial en Madrid, profesor de gramática y retórica, escribe una gramática que, partiendo del Arte Regia y de Álvares, sirva para enseñar gramática latina siguiendo los métodos jesuitas. Era un intento de renovar y completar lo existente y, sobre todo, de frenar a los nuevos métodos racionales. Como Prefecto, Vargas había supervisado las gramáticas latinas que los autores utilizaban en las aulas (Martínez Gavilán, 2008: 201; Bartolomé, 1980: 138-139), de manera que es lógico, por un lado, su conocimiento de los métodos del Arte Regia y de Álvares, y por otro lado su preocupación ante la aparición de métodos racionales, que prometían brevedad, sencillez, utilidad y lógica.

Vargas conocía la situación privilegiada con la que partía, pero era consciente de que la doctrina racional empezaba a extenderse. No en 
vano, se habían incluido aspectos de doctrina racional en la obra de Álvares y en el Arte Regia. Y, de hecho, es significativo que, en su Elucidata, Vargas ataca la doctrina del Brocense sobre los verbos neutros, no citando la propia Minerva, sino el largo catálogo de verbos que aparecían también considerados falsamente como neutros en las notas del Arte Regia. Es decir, Vargas sigue en la sintaxis el Arte Común, pero critica aspectos en los que dicho Arte había admitido doctrina sanctiana.

Además, era consciente también de que algunos discípulos del Brocense como Diego López, o Caro y Cejudo, con el pretexto de comentar el libro IV del Antonio, en realidad introducían doctrina racional. Y ciertamente, él conocía dichos comentarios porque, como hemos mostrado, cita en su Elucidata la Explicación de Caro y Cejudo, en una edición de 1705 (publicada, pues, seis años antes que la Elucidata) que se vendía en la calle Toledo, junto al Colegio Imperial.

Todo ello se unía a las noticias que llegaban a España sobre el éxito de Sanctius en Europa, con seguidores como Beauzée o Lancelot, que estaban dando pie a una doctrina gramatical en la que predominaba la defensa de dos niveles en el lenguaje, el uso de la elipsis como mecanismo gramatical básico, o el estudio de la gramática con un enfoque enciclopédico, lógico, filosófico, didáctico, breve, claro y, en cualquier caso, con un método totalmente alejado de la memorización jesuítica, promoviendo que la luz de la razón se extendiera a todos los ámbitos ${ }^{30}$.

Es esa amenaza la que llevó a Vargas a escribir la Elucidata, una obra que promete ser ella quien ilumine la gramática. En esta obra, Vargas expone su método y, aun sin nombrar casi al Brocense, y utilizando para sus críticas términos generales como «aduersarii, plures, alii...», aun sin citar pasajes concretos de la Minerva, sí ataca los métodos racionales por sus definiciones poco claras, por el abuso de la elipsis, y sobre todo por basarse en una ratio general y lógica, frente a las rationes que parten del uso de los autores clásicos, que son las únicas rationes que admiten los jesuitas.

${ }^{30}$ Como apunta Espino (2010: 71-72): «El método port-royalista traía un tipo de enseñanza del latín más reflexiva, clara y rápida frente a la oscuridad, complejidad y densidad ignaciana». 


\section{BIBLIOGRAFÍA CITADA}

\section{Ediciones}

Álvares, M. [1572] (2001): De institutione grammatica libri tres. R. Ponce de León (ed.). Tesis Doctoral. Universidad Complutense de Madrid (en línea: $<$ https://eprints.ucm.es/5134/> [consulta: 9 de enero de 2019]).

— [1572] (2002): Emmanuelis Aluari Societate Iesu De institutione grammatica liber secundus. De octo partium orationis constructione. J.M. Gómez Gómez (ed.). Cáceres, Universidad de Extremadura.

Caro y Cejudo, G.M. [1607] (1728): Explicación del Libro IV y V del Arte nuevo de gramática. Madrid, Francisco Manuel Álvarez.

De LA CERDA, J.L. [1601] (2013): El Arte Regia. Nebrija reformado. J.M. Gómez Gómez (ed.). Cáceres, Universidad de Extremadura.

García De VARGaS, J. [1711]: Elucidata Grammatica Latina, Madrid, Gabriel de Barrio.

— [1711] (2018): Antibrocensis Crisis. M.L. Harto Trujillo (ed.). Cáceres, Universidad de Extremadura.

SÁNCHEZ dE LAS BROZAS, F. [1587] (1995): Minerva o de causis linguae Latinae. E. Sánchez Salor -I, III y IV- y C. Chaparro -II- (eds.). Cáceres, Institución Cultural El Brocense.

\section{Estudios}

BARTOLOMÉ, B. (1980): «Las escuelas de gramática del Colegio Imperial de Madrid durante el siglo XVII». Anales del Instituto de Estudios Madrileños, 17, págs. 137-157.

- (1995): «Educación y humanidades clásicas en el Colegio Imperial de Madrid durante el siglo XVI». Bulletin Hispanique, 97, págs. 109-155.

BASSOls DE Climent, M. (1945): Sintaxis histórica de la lengua latina. Barcelona, CSIC.

Breva Claramonte, M. (1980): «La teoría gramatical del Brocense en los siglos XVII y XVIII». Revista Española de Lingüística, 10.2, págs. 351-371.

CAÑIGRAL, L. de (1978): «Un humanista valdepeñero: Jerónimo Martin-Caro y Cejudo (1630-1712). Bibliografía». Cuadernos de estudios manchegos, 8, págs. 45-80.

— (1989): «El Brocense y su mayor campeón, su más acérrimo secuaz y su más valiente capitán, D. Jerónimo Martín Caro y Cejudo». En: Actas del Simposio Internacional IV Centenario de la publicación de la Minerva del Brocense. Cáceres, Institución Cultural El Brocense, págs. 101-110. 
ESPARZA, M.A. (2006) «La recuperación de la obra gramatical de Nebrija en el siglo XVIII». En Gómez Asencio, J.J. (dir.): El castellano y su codificación gramatical. III: De 1700 a 1835. Salamanca, Fundación Instituto Castellano y Leonés de la Lengua, págs. 99-124.

EsPINO, J. (2005): Evolución de la enseñanza gramatical jesuítica en el contexto socio-cultural español entre los siglos XVI y primera mitad del XVIII, Madrid.

- (2010): «Los jesuitas frente al racionalismo del Brocense: la enseñanza del latín en la España de los siglos XVII y XVIII». Calamus Renascens, 11, págs. 61-87.

Gómez GómEz, J.M. (2002): Emmanuelis Aluari e Societate Iesu De institutione grammatica liber secundus de octo partium orationis constructione. Estudio, edición crítica, traducción, notas e índices. Cáceres, Universidad de Extremadura

- (2013): El Arte Regia: Nebrija reformado por Juan Luis de la Cerda: morfología y sintaxis. Cáceres, Universidad de Extremadura.

LÁZARO CARRETER, F. (1985): Las ideas lingüísticas en España durante el siglo XVIII. Barcelona, Crítica.

Martínez GaVilán, M.D. (2008): «Las fuentes del De Institutione Grammatica del P. de la Cerda: Racionalismo sanctiano y pedagogía jesuítica en el Arte de Nebrija reformado». En Maqueira, M. y Martínez, M.D. (eds.): Gramma-Temas 3: España y Portugal en la tradición gramática, León, Universidad de León, págs. 199-238.

Merino Jerez, L. (1989): «Diego López o la presencia de la Minerva en el Arte reformado de Nebrija». En: Actas del Simposio Internacional IV Centenario de la publicación de la Minerva del Brocense. Cáceres, Institución Cultural El Brocense, págs. 189-201.

MoRCILlo EXPósito, G. (2002): La gramática de Diego López. Estudio y edición. Cáceres, Universidad de Extremadura.

PonCE DE León, R. (2001): Aproximación a la obra de Manuel Álvares. Edición crítica de sus "De institutione grammatica libri tres». Tesis doctoral. Universidad Complutense de Madrid (en línea: < https://eprints.ucm.es/5134/> [consulta: 9 de enero de 2019]).

- (2003): «La difusión de las artes gramaticales latino-portuguesas en España (siglos XVI-XVII)». Península. Revista de estudios ibéricos, 0, págs. 119-145.

- (2004): «Contra el Brocense. En torno a la teoría sintáctica de J. García de Vargas». En Corrales, C. et al. (eds.): Nuevas aportaciones a la historiografía lingüística. Madrid, Arco Libros, págs. 1295-1304. 
- (2005): «Fuentes españolas en la primera polémica gramatical portuguesa del siglo XVIII (1721-1736)», Península. Revista de estudios ibéricos, 2, págs. 365-375.

RAMAJO CAÑO, A. (1991): «La huella del Brocense en el Arte del P. la Cerda (15601643)». Revista Española de Lingüística, 21.2, págs. 301-321.

RODRíGUEZ ANICETO, C. (1931-1932): «Reforma del arte de Antonio de Lebrija». Boletín de la Biblioteca Menéndez Pelayo, extra 1, págs. 228-242.

SÁNCHEZ SAlOR, E. (1999): «La gramática de Nebrija reformada». En Martins Melo, A.M. (coord.): Actas do I Congresso Internacional Humanismo novilatino e pedagogia, Braga, Universidade Católica Portuguesa, págs. 99-129.

- (2000a): «Un Nebrija reformado en Zaragoza (1610)». Calamus Renascens, 1, págs. 349-350.

- (2000b): «La fortuna europea del Brocense». En Fernández-Daza, M. et al. (eds.): El humanismo extremeño. Trujillo, Real Academia de Extremadura, págs. 207-222.

- (2002): De las elegancias a las causas de la lengua: retórica y gramática del humanismo. Alcañiz-Madrid, CSIC-IEH.

- (2012): La gramática en Europa durante el siglo XVII. Dispersión doctrinal. Alcañiz-Madrid, CSIC-IEH.

URIARTE, J.E. de (1906): Catálogo razonado de obras anónimas y seudónimas de autores de la Compañía de Jesús pertenecientes a la antigua asistencia española, Madrid, Sucesores de Rivadeneyra.

VERNEY, L.A. (1760-1768): Verdadero método de estudiar para ser útil a la República y a la Iglesia (5 vol.). Madrid, Joaquín Ibarra.

María Luisa HARTO TRUJILlo

Universidad de Extremadura mlharto@unex.es 0000-0001-6807-0230 
